Cordelia Miller (Berlin)

\title{
Sinfonische Orgelmusik nach 1870 zwischen Sakralität, Profanität und Nationalismus Ein deutsch-französischer Vergleich
}

Wenn wir uns mit sinfonischer Orgelmusik beschäftigen, sprechen wir einerseits von einer bzw. mehreren auf die Orgelmusik übertragenen Eigenschaften, die für das "Sinfonische“ stehen, andererseits von einer Gattung, der sogenannten „Orgelsinfonie“. Im deutschfranzösischen Vergleich fällt auf, dass trotz oder, wie zu zeigen sein wird, gerade wegen einer ungebrochenen sinfonischen Tradition, aufgrund derer der Begriff des Sinfonischen bzw. des „sinfonischen Stils“ überhaupt erst entstanden ist, zwar sinfonische Aspekte, nicht jedoch die Orgelsinfonie als Gattungsbezeichnung Eingang in die deutsche konzertante Orgelmusik fanden. In Frankreich dagegen, wo die Sinfonie als die repräsentative Gattung des Sinfonischen im 19. Jahrhundert im Vergleich zur Oper nur eine Nebenrolle spielte, etablierte sich mit der Orgelsinfonie eine neuartige, spezifisch französische Gattung. Die folgenden Ausführungen gehen der Frage nach, wie es zu dieser paradoxen gattungsgeschichtlichen Situation kommen konnte. Dazu soll im ersten Teil betrachtet werden, unter welchen musik- und kulturhistorischen Voraussetzungen das Sinfonische und die Sinfonie in Frankreich seit den 1870er Jahren an Bedeutung gewinnen und die Gattung der Orgelsinfonie, wie sie von Charles-Marie Widor (1844-1937) entwickelt wurde, entstehen konnte. Im zweiten Teil stehen Aspekte des Sinfonischen in der deutschen Orgelmusik, wofür am Ende des Jahrhunderts das Orgelwerk von Max Reger (1874-1916) repräsentativ steht, im Mittelpunkt. Die unterschiedlichen Entwicklungen in den beiden Orgelnationen im Hinblick auf sinfonische Orgelmusik reflektieren das Spannungsfeld aus Sakralität, Profanität und Nationalismus, in dem sich die jeweilige Orgelmusikproduktion jener Epoche bewegte.

\section{Die Idee des Sinfonischen in der französischen Musikästhetik um 1870}

Das Primat der Sinfonie als der höchsten Gattung der Instrumentalmusik entstand auf der Grundlage des sich in der deutschen Romantik etablierenden Ranges der Instrumentalmusik als der aufgrund ihrer Immaterialität höchsten, weil autonomen und „reinen“ Kunst. Hinzu kam die z. B. bei Robert Schumann herausgehobene demokratisch-bürgerliche Idee von der Gleichberechtigung aller Instrumente in der Sinfonie. Beethovens Sinfonien wurden in Deutschland, aber seit den 1830er Jahren auch in Paris „zum Inbegriff der Gattung, zum ,non plus ultra' der Symphonik und bestimmten auch die normativen Grundlagen der Komposition, insbesondere die gattungsinhärente ästhetische Idee symphonischer Monumentalität und Größe“1. Dabei beinhaltet der

1 Christiane Strucken-Paland, „Symphonische Züge in César Francks Grande pièce symphonique“, in: Dies. und Ralph Paland (Hrsg.), César Franck im Kontext. Epoche, Werk und Wirkung, Köln ${ }^{2} 2015$, S. 101-119; hier S. 104. 
„Begriff des Symphonischen [...] eine Auskunft über die Dimension sowie eine Auskunft über die Form, welche sich einerseits in dem zugrunde liegenden Gerüst des Sonatensatzes und andererseits in der ästhetischen Idee der Einheit des Werkganzen manifestiert. Diese beiden zentralen Momente des Symphonischen [...] sind untrennbar miteinander verbunden." 2

Die Dimension der Sinfonie erwächst einerseits aus der schieren Größe des Klangkörpers, andererseits aus ihrem Rezeptionskontext, indem sie sich im Gegensatz zur Kammermusik an ein großes, öffentliches, bürgerliches Publikum richtet und dadurch „universalistischen Charakter "3 gewinnt. Im Hinblick auf die Aussage über die Form verbindet sich im Begriff des Sinfonischen mit „dem ästhetischen Postulat der Einheit des Werkganzen [...] in dialektischer Weise zugleich auch die Forderung nach größtmöglicher Mannigfaltigkeit. [...] Die Musikästhetik des 19. Jahrhunderts forderte einen formal geschlossenen Zusammenhang ohne den Verzicht auf charakteristische individuelle Prägungen. " ${ }^{4}$ Beides gewährleistet das Schema des klassischen, mehrsätzigen Sonatenzyklus mit den jeweils verschiedenen Ausdruckscharakteren der einzelnen Sätze und Satzteile einerseits und einem reichen motivisch-thematischen Beziehungsgeflecht andererseits.

In Frankreich gewannen das Sinfonische und die Sinfonie im historischen Kontext des Deutsch-französischen Krieges von 1870/71 an Bedeutung, wobei die beiden zentralen Aspekte der Dimension und der Form vor dem Hintergrund der eigenen Musiktraditionen einerseits und der übermächtigen deutschen sinfonischen Tradition andererseits im Verbund mit dem Streben nach einer genuin französischen Musik auf eine sehr spezifische Weise rezipiert und künstlerisch umgesetzt wurden. Die allgemeine Kritik an der Verflachung der französischen Musikkultur verband sich unter dem Eindruck des nationalen Traumas des verlorenen Krieges mit der Suche nach einem neuen Nationalbewusstsein, eine Verbindung, die sich in der Leitidee einer ars gallica äußerte und in der 1871 gegründeten Société Nationale de musique einen institutionellen Rahmen finden sollte:

„Getragen durch ein elitäres Kunstverständnis ganz im Sinne des ,l'art pour l’art' [...] und unter Berufung auf die erstarkende nationale Besinnung, ging es der hier versammelten jüngeren Komponistengeneration ganz explizit um die Beförderung sogenannter ,musique sérieuse ‘. Die zunehmende Seichtheit, die im musikalischen Schaffen der vergangenen Jahrzehnte zu beobachten gewesen war, habe den moralischen Zustand der Nation geschwächt und zu einer Entnationalisierung beigetragen, der es durch eine ernste nationale Musikkultur gegenzusteuern gelte."

Die „musique sérieuse“ grenzte sich von der Welt der Oper und der (Klavier-)Virtuosität und der sie verbindenden Gattungen der Variation und Fantasie ab und stellte „idealiter eine abgeschirmte Gegenwelt dar" “6, in der der Instrumentalmusik vor allem unter Berufung auf ethisch-moralische Gesichtspunkte die Führungsrolle zugewiesen wurde. Indem

2 Ebd.

3 Ebd., S. 105.

4 Ebd.

5 Fabian Kolb, „Symphonik im ,style d'orgue'? Zu César Francks Symphonie d-Moll und den Grundlagen, Problemen und Chancen eines rezeptionsästhetischen Topos“, in: Ebd., S. 61-99; hier S. $69 f$.

6 Martin Kaltenecker, „César Franck und der Diskurs des Organizismus“, in: Ebd., S. 143-160; hier S. 149. 
die Komponisten der Wiener Schule, darunter in erster Linie Beethoven, die Protagonisten dieser Bewegung waren, eignete man sich eine ausgeprägt deutsche Tradition an, die man zugleich in „einem Akt kultureller Annektierung zu überbieten trachtete. "7 Auf diskursiver Ebene geschah dies durch „die Verquickung einer Rezeption deutscher Musik mit Begriffen [...], die aus der französischen Ästhetik des 18. Jahrhunderts stammen “8, wie „goût“, „mesure“, „simplicité“ und vor allem „clarté“, aber auch der weiterhin positiv besetzte Begriff des ,effet",

„der mit einer effizienten rhetorischen Anlage in Verbindung steht. Diese bestimmt auch die Wichtigkeit des melodischen Elements als des führenden und quasi zum Hörer sprechenden: Melodie darf weder von Konstruktion zerstört werden (von allzu weit getriebener thematischer Arbeit) noch von der Instrumentierung verunklart. “9

Damit entstand im Paris der 1840er bis 1860er Jahre eine Ästhetik der Instrumentalmusik, die im Sinne einer „musique pure“ und der Sinfonie als ihrem Ideal einerseits in Parallelität zur deutschen Ästhetik stand, die sich andererseits aber durch das Primat der Melodie von ihr absetzte. Bezogen auf die französische Beethoven-Rezeption, die aus dem Diskurs um die „musique sérieuse“ hervorging, und ihre Manifestation im sinfonischen Schaffen französischer Komponisten bedeutete dies, dass sie sich zwar auf Beethoven'sche Formmodelle - insbesondere das zyklische Prinzip - beriefen, dabei aber sowohl auf die Stringenz der thematisch-motivischen Arbeit und die daraus erwachsende dynamische Spannung als auch auf das Pathos des großen Vorbildes weitgehend verzichteten. ${ }^{10}$ Bei der Mehrzahl der französischen Instrumentalkompositionen um 1870 kann man daher von einer „selektiven Beethoven-Rezeption“11 sprechen, bei der der Komponist „in der Hauptsache wie ein Reservoir von Gesten und Affekten benutzt worden zu sein [scheint], als eine Art Steinbruch von rhythmischen und melodischen Gesten“12. Der selektive Charakter der

7 Kolb, „Symphonik im ,style d'orgue?"“, S. 70.

8 Kaltenecker, „César Franck und der Diskurs des Organizismus“, S. 150.

9 Ebd. Der "goût français“, der in den Auseinandersetzungen um die Vorherrschaft der italienischen oder französischen Oper in Paris zum Symbol nationaler Überlegenheit wurde, basierte auf dem Primat des Vorrangs der Poesie vor der Musik und folglich auch der Vokal- vor der Instrumentalmusik. Die irrationale und undefinierbare Ausdruckskraft der absoluten Musik galt gegenüber der das Wort untermalenden Musik als ästhetisch und ethisch von geringerem Wert. Der unanfechtbare Vorrang der Poesie vor der Musik führte zur Forderung nach „clarté" und „simplicité “ im Sinne von Verständlichkeit und Fasslichkeit. Die italienische Oper wurde nicht nur wegen der fremden Sprache, sondern auch wegen der angeblich darin enthaltenen „difficultés“ abgelehnt. Damit waren Koloraturen und virtuose Instrumentaleinlagen ebenso gemeint wie komplizierte musikalische Strukturen und „übertriebene“ Expressivität. Im späteren 19. Jahrhundert, als Deutschland im Musikbereich zum nationalen „Hauptkonkurrenten" wurde, übertrug man interessanterweise die gleichen Kritikpunkte - Kompliziertheit, Überladenheit, Maßlosigkeit - auf die deutsche Musikproduktion. Zur Auseinandersetzung um den "goût français", die in der Mitte des 18. Jahrhunderts im sogenannten Buffonistenstreit gipfelte, vgl. Eeva-Taina Forsius, Der "goût français“ in den Darstellungen des Coin du Roi. Versuch zur Rekonstruktion einer "Laienästhetik" während des Pariser Buffonistenstreites 1752-1754. Haltungen, Widersprüche, Bezüge zur Vorgeschichte und zur ästhetischen Tradition (= Frankfurter Beiträge zur Musikwissenschaft 18), Tutzing 1985.

10 Zum sinfonischen Schaffen französischer Komponisten nach 1871 vgl. Elisabeth Schmierer, „Zwischen Nationalismus und Kosmopolitismus. Französische Symphonik nach 1871“, in: Jahrbuch des Staatlichen Instituts für Musikforschung 2001, S. 92-109.

11 Kaltenecker, „César Franck und der Diskurs des Organizismus“, S. 159.

12 Ebd., S. 156. 
Rezeption der deutschen Sinfonie- und Beethoven-Tradition wurde dadurch begünstigt, dass es, anders als in Deutschland, in Frankreich keine ungebrochene sinfonische Tradition gab, was zu einer Offenheit und Durchlässigkeit eigener Sinfoniekonzepte führte, ohne die die Entstehung der paradoxen Gattung der Orgelsinfonie wohl kaum denkbar gewesen wäre. Ein gutes Beispiel für die selektive französische Beethoven-Rezeption ist das musikalische Schaffen von César Franck (1822-1890), der als Mitbegründer der Société Nationale de musique eine Vorreiterrolle in der Bewegung der „musique sérieuse“ einnahm und zugleich mit der erstmaligen Einbeziehung sinfonischer Elemente in die Orgelmusik dazu beitrug, dass die Orgel ins Zentrum dieser Bewegung rückte und damit einen historisch einzigartigen kulturellen, gesellschaftlichen und nationalen Stellenwert erhielt. ${ }^{13}$ Francks kammermusikalische Werke, seine Sinfonie wie auch seine sinfonisch angelegten Orgelwerke zeichnen sich durch eine „anti-dynamische Struktur“ mit der „Grundtendenz zu statischer Aneinanderreihung “ aus, ${ }^{14}$ bei der Themen und Motive nicht entwickelt werden, sondern die Funktion erfüllen, Sätze und Satzteile im Sinne einer „Reminiszenz und als poetisches Echo“ 15 miteinander zu verbinden. Sein „Komponieren scheint darin zu bestehen, Situationen zu schaffen, die eine quasi unveränderte, aber intensivierte und bohrende Rückkehr von melodischen Elementen ermöglichen. Francks Musik erweist sich hier als involutiv, sie will einmünden ins Gewesene." 16 Was ihn an Beethovens sinfonischer Arbeit interessiert, ist „das Element der zyklischen Verklammerung “17, in dem sich seine aktive Beethoven-Rezeption denn auch erschöpft. Dennoch genügte dieser sehr selektive Rückgriff auf Beethoven'sche Formmodelle, der in der Art seiner Aneignung ein mit der Entwicklungslosigkeit geradezu konträres musikalisches Ergebnis zeitigte, im Verbund mit dem Postulat der „musique sérieuse“ in den Augen der „jeune école française“, um Franck zum Beethoven-Nachfolger zu stilisieren.

\section{Voraussetzungen für Aspekte des Sinfonischen in der französischen Orgelmusik um 1870}

Dass, um auf unser Thema zurückzukommen, Elemente des Sinfonischen Eingang in die französische Orgelmusik finden konnten, war also unter der Voraussetzung des Strebens nach einer neuen Ernsthaftigkeit und Geistigkeit in der „musique sérieuse“ im Verbund mit der Suche nach dem National-Eigenen und kultureller Hegemonie sowohl mittels einer Rückbesinnung auf die eigene Vergangenheit als auch in der Ausrichtung an der europäischen Musikgeschichte, insbesondere an Beethoven, möglich. Dabei profitierten die Orgelkomponisten von den Bestrebungen des nationalen Neokatholizismus ebenso wie von der allgemeinen Sakralisierung von Musik im Sinne einer Ersatzreligion. Diskursgeschichtlich handelte es sich also um „eine Sakralisierung und Nationalisierung des Musikverständnisses"18 als Voraussetzung für die spezifische Entwicklung der franzö-

13 Der personelle Faktor, dass Franck wie auch Camille Saint-Saëns, die beide als Organisten an bedeutenden Pariser Kirchen wirkten - Franck in Ste. Clotilde, Saint-Saëns in Madeleine - und sich bewusst gegen den mondänen Orgelstil eines Louis Lefébure-Wely stellten, zentrale Figuren der S.N.M. waren, dürfte entscheidend für diese Entwicklung gewesen sein.

14 Kaltenecker, „César Franck und der Diskurs des Organizismus“, S. 159.

15 Ebd., S. 157.

16 Ebd., S. 153. Oder, wie Stockhausen es formulierte: „Immer dasselbe in ständig neuem Licht.“ Zitiert nach: Ebd., S. 160.

17 Ebd., S. 159.

18 Kolb, „Symphonik im style d'orgue?'“, S. 75. 
sischen Orgelmusik um 1870. Die Orgel avancierte - nicht nur in Frankreich, aber hier mit der deutlicheren Konsequenz ihrer Aufwertung - zum „Instrument der Transzendenz [und] Signum eines religiösen Ästhetizismus"19, nicht allein im kirchlich-funktionalen Bereich, sondern auch im Hinblick auf die liturgisch nicht gebundene Orgelmusik. Kunstreligiöse Vorstellungen, „die das kontemplative Hören absoluter Musik in die Nähe religiöser Versenkung brachten “ 20 und dem Religiösen den Aspekt des Erhabenen entgegensetzten, ließen die Grenze zwischen religiöser und profaner Musik sowie „zwischen einer ,säkularisierten' Orgelmusik und einer ,sakralisierten' Symphonik “21 verschwimmen, zumal gerade die Sinfonik mit dem Erhabenen assoziiert wurde.

Im Zuge einer Rückbesinnung auf die Vergangenheit der Grande Nation ließ sich an die Tradition französischer Orgelkunst in der Ära von Louis XIV. anknüpfen, die im Inund Ausland als spezifisch nationale Musik und nationaler Sonderweg aufgefasst wurde. Spätestens mit Jacques-Nicolas Lemmens (1823-1881) und seinem „bon style“ erwuchs aus Sicht der Verfechter der „musique sérieuse“ ein veritabler Erbe des organistischen „siècle classique“. 22 Der Rekurs auf die Tradition bezog sich jedoch nicht allein auf die französische Schule, sondern auch auf J. S. Bach. Dabei wurde eine Synthese der Musiktraditionen Deutschlands und Frankreichs angestrebt. Als vorbildlich in dieser Hinsicht galt Alexandre-Pierre-François Boëly (1785-1858), dem Lemmens, Camille Saint-Saëns, Franck und Widor folgten. In ihrem Werk vereinigten sich „Klangpracht, Farbreichtum, dramatische Expressivität und Primat der Melodie als französische Qualitäten plus Formsinn, polyphoner Reichtum und Verarbeitungs- bzw. Fortspinnungstechniken als deutscher Zugewinn" ${ }^{23}$. Dadurch avancierten diese Orgelkomponisten sogar zum Vorbild bzw. im Fall von César Franck zum Bindeglied für das französische Schaffen auf sinfonischem Gebiet, wobei dort die Rolle Bachs durch diejenige Beethovens ersetzt wurde. ${ }^{24}$

Dass die französische Orgelmusik zum „patriotischen ,Bollwerk““ 25 einer neuen nationalen Musik erhoben wurde, wäre schließlich nicht denkbar gewesen ohne die epochalen orgelbaulichen Neuerungen der Firma Cavaillé-Coll. Vor allem nach 1871 verstand man die „technologisch-kulturelle Leistung ersten Ranges“ explizit „als Rückkehr zur großen Zeit der französischen Orgelkultur und als Beitrag zur Rückgewinnung der kulturellen

19 Ebd., S. 70.

20 Strucken-Paland, „Symphonische Züge in César Francks Grande pièce symphonique“, S. 106.

21 Kolb, „Symphonik im style d'orgue?"', S. 73. Für das Verschwimmen dieser Grenze steht repräsentativ Francks kompositorisches Schaffen. Seine Orgelzyklen Six Pièces d'orgue und Trois Pièces pour le Grand Orgue sind in ihrer orchestralen Klanglichkeit und formalen Struktur sinfonisch und damit säkular „gedacht", und umgekehrt wurde seine Sinfonie d-Moll schon von der zeitgenössischen Rezeption als im „style d'orgue" und folglich sakral konzipiert wahrgenommen.

22 Auch Franck rekurriert mit der Titelgebung seiner Six Pièces d'orgue und der Trois Pièces pour le Grand Orgue gattungsgeschichtlich an die Livres d'orgue des 17. und 18. Jahrhunderts an.

23 Kolb, „Symphonik im ,style d'orgue?"“, S. 72.

24 Um die Rückbesinnung und Berufung auf Bach zu untermauern, wurden musikalische Genealogien kreiert, die die genannten französischen Orgelkomponisten in die direkte Nachfolge Bachs stellten. Dabei handelte es sich meist um Legenden, wie im Fall von Widor, der sein Leben lang daran festhielt, Erbe einer Tradition zu sein, die über Lemmens, Adolph Hesse und Johann Nikolaus Forkel direkt auf Bach zurückführte. Dabei konnte weder Forkel als Nachgeborener ein Erbe Bachs sein, noch berechtigte Lemmens' sehr kurze Unterrichtszeit bei Hesse seine Stilisierung zum legitimen Hüter der Bach-Tradition.

25 Kolb, „Symphonik im, style d'orgue?", S. 73. 
Vormachtstellung im internationalen Wettbewerb“26. Zwischen 1840 und 1890 baute Aristide Cavaillé-Coll (1811-1899) Orgeln für sämtliche bedeutende Pariser Kathedralen, von St. Denis bis St. Sulpice und Notre Dame, aber auch für Theater, Konzertsäle und Ausstellungsgebäude, darunter den Trocadéro-Palast, das zentrale Gebäude der Weltausstellung von 1878. Obwohl Frankreich mit dem Bau dieser ersten Konzertsaalorgel zeitlich weit hinter England und Deutschland lag, ${ }^{27}$ bedurfte es nicht erst dieser institutionellen Voraussetzung für eine Wahrnehmung der Orgel als säkulares Instrument, auf dem säkulare Gattungen erklingen, zumal sich die Trocadéro-Orgel von den großen Pariser Kathedralorgeln nicht substantiell unterschied. Zwar durften Orgelkonzerte in den katholischen Kirchen Frankreichs aus dogmatischen Gründen traditionell nicht stattfinden, ${ }^{28}$ allerdings fanden die Organisten Wege, um die klangprächtigen und prestigeträchtigen Orgeln Cavaillé-Colls, die sie zu einer entsprechenden Musik inspirierten, im Sinne konzertanter Aufführungen zu Gehör zu bringen. Bereits 1864, 14 Jahre vor der Einweihung der ersten Konzertsaalorgel, wandte sich Franck in einer „séance“, in der er seine Six Pièces d'orgue erstmals öffentlich spielte, bewusst an ein Konzertpublikum und wagte es somit erfolgreich, seinen Arbeitsplatz, die Kirche Ste. Clotilde, in einen Konzertsaal umzufunktionieren. Widor verstand es während seiner über 60 Jahre währenden Dienstzeit als Titularorganist an der berühmten Cavaillé-Coll-Orgel in St. Sulpice, die Sonntagsmesse in ein allwöchentliches Konzert umzuwandeln. In seinen Memoiren beschreibt der polnische

26 Arnfried Edler, Gattungen der Musik für Tasteninstrumente, Teil 3: Von 1830 bis zur Gegenwart, Laaber 2004, S. 146.

27 In England wurden bereits um die Mitte des 18. Jahrhunderts Konzertsäle mit Orgeln ausgestattet, z.B. die Rotunden der Londoner Pleasure Gardens; in die 1834 von dem Industriellen Joseph Moore gebaute Town Hall in Birmingham, die als der schönste Konzertsaal der Welt galt, baute William Hill aus London eine große Orgel ein, auf der auch Mendelssohn erfolgreich konzertierte und die ihn zu seinen Orgelsonaten inspirierte. In Deutschland wurden Konzertsaalorgeln zunächst aus der Erfordernis einer Begleitfunktion heraus installiert, und zwar im Zusammenhang mit den Musikfesten, die vor allem im Rheinland „seit dem frühen 19. Jahrhundert Repräsentanten einer neuen bürgerlichen Gesellschaft als Träger der Musikkultur waren.“ Klaus Wolfgang Niemöller, „Perspektiven der europäischen Konzertsaalorgel in der Musikgeschichte des 19. und frühen 20. Jahrhunderts“, in: ders. (Hrsg.), Die Orgel im Konzertsaal und ihre Musik. Bericht über das Symposion Sankt Petersburg 14.-15.1.2005 (= Edition IME Reihe I: Schriften Band 15), Sinzig 2010, S. 13-34; hier S. 19f. Mendelssohn, der in England nicht nur die Orgelkonzertkultur in den großen Town Halls kennengelernt hatte, sondern auch die ungebrochene Tradition der Aufführung der Händel'schen Oratorien, initiierte als vielfacher Leiter der Niederrheinischen Musikfeste ihre originalgetreue Wiedergabe mit Orgelbegleitung. (Zu Mendelssohns diesbezüglichem Engagement vgl. Niemöller, ebd., S. 19-24.) Seit der zweiten Hälfte des 19. Jahrhunderts gehörte eine repräsentative Orgel mit meist drei Manualen, Pedal und mindestens 40 Registern zur Grundausstattung eines jeden größeren Konzertsaals. Anders als in England oder den USA, wo sich dank der Konzertsaalorgeln eine spezifische, außerkirchliche, dabei äußerst erfolgreiche Orgeltradition etablierte, in der die Orgel in erster Linie als Orchesterersatz fungierte, wurde die Orgel in Deutschland auch im Konzertsaal weiterhin primär als Kircheninstrument wahrgenommen. Bis heute erfüllt sie dort vor allem repräsentative und dekorative Zwecke.

28 Alexandre Guilmant (1837-1911) beispielsweise durfte in seiner Amtskirche La Trinité nicht konzertieren. Er verlagerte daher seine Aktivitäten als Konzertorganist und Komponist von explizit konzertanter Orgelmusik auf Konzertsäle in England und Amerika, die er während seiner ausgedehnten Tourneen frequentierte, sowie auf den Trocadéro-Palast in Paris, wo er nicht nur das Eröffnungskonzert am 7. August 1878 bestritt, sondern von 1879 bis 1898 und noch einmal von 1901 bis 1906 eine lange Reihe von „Concerts historiques“veranstaltete Gesprächskonzerten, in denen er das Publikum vor allem mit den Alten Meistern vertraut machte. 
Pianist und Politiker Ignace Jan Paderewski, wie sich Sonntag für Sonntag ein exquisites Publikum um den Orgelvirtuosen drängte:

„[...] Widor's famous organ recital every Sunday morning was a rendezvous of the whole aristocratic and artistic Paris world. The church was always crowded with the most brilliant gathering of beautiful and fashionable ladies. [They came] as near to the organ and Widor as they could possibly get. [...] To hear Widor on Sunday morning at St. Sulpice became a habit and a fashion that lasted many years." 29

Wie bedeutsam die Cavaillé-Coll-Orgel für die Entwicklung des französischen Selbstbewusstseins als Musiknation und der Orgelmusik als ihrem Aushängeschild war, belegt auch die Selbstverständlichkeit, mit der sie von Widor u. a. als die Vollendung der gesamteuropäischen orgelbaulichen Entwicklungsgeschichte betrachtet wurde. In dieser Sichtweise, die die Barockorgel lediglich als ein Bindeglied ansah, ließ sich auch das Bach'sche Orgelwerk durch die Überzeugung, dass erst die Cavaillé-Coll-Orgel eine adäquate Wiedergabe möglich gemacht habe, national vereinnahmen. Widor, der sich in der Zusammenarbeit mit Albert Schweitzer intensiv mit dem Orgelwerk Bachs auseinandersetzte, ${ }^{30}$ war der Überzeugung, dass erst die technischen Erneuerungen Cavaillé-Colls, die mit der Verbesserung der Windversorgung und den unbeschränkten Koppelmöglichkeiten eine bruchlose Klangsteigerung ermöglichten, Bachs Vorstellungen von einer „absolut einheitliche[n] Klanglichkeit“31 zu realisieren vermochten. Mit ihnen sei „uns die Möglichkeit gegeben, die Riesenschöpfungen des Eisenacher Meisters zu durchdringen, sie in ihrem ganzen Glanze, in rechtem Lichte zu schauen und Bach zu hören, wie Bach gehört sein will.“32 Die Vorstellung von der Cavaillé-Coll-Orgel als idealem Bach-Instrument ${ }^{33}$ verband sich in Widors Orgelästhetik mit der Hinwendung zum Komponisten ausdrucksstarker Vokalund Orchestermusik, deren Grundcharakter Widor in Bachs Orgelwerk wiederzufinden

29 Ignace Jan Paderewski/Mary Lawton, The Paderewski Memoirs, London 1939, S. 152. Offenbar war es aufgrund der großen Entfernung zur Messzeremonie, ihrer einheitlichen Struktur und zeitlichen Ausdehnung möglich, dass parallel dazu und weitgehend unabhängig davon eine konzertähnliche Situation auf der Orgelempore bestehen konnte, die in der Nachfolge Widors viele berühmte Pariser Organisten nutzten, um eine sehr spezifische französische Orgelkonzertkultur zu etablieren.

30 Albert Schweitzer (1875-1965) kam 1893 nach Paris, um bei Widor zu studieren. Ihr anfängliches Lehrer-Schüler-Verhältnis entwickelte sich jedoch bald zu einem gegenseitigen Geben und Nehmen auf Augenhöhe. Schweitzer half Widor, die Bachs Choralvorspielen zugrundeliegenden Texte und ihre musikalische Ausdeutung zu verstehen. Eine langjährige Zusammenarbeit im Bereich der BachForschung entstand, die sich in zahlreichen Veröffentlichungen niederschlug, darunter in Schweitzers wegweisender Bach-Monographie Jean-Sébastien Bach - le Musicien-Poète, die 1905 erstmals erschien und zu der Widor das Vorwort schrieb, wie auch zur 1908 herausgebrachten deutschen Fassung.

31 Charles-Marie Widor, Vorrede zu: Emile Rupp, Die Entwicklungsgeschichte der Orgelbaukunst, Einsiedeln 1929, S. XII.

32 Charles-Marie Widor, Die Technik des modernen Orchesters. Ein Supplement zu H. Berlioz Instrumentationslehre. Aus dem Französischen übersetzt von Hugo Riemann, Leipzig 1904, S. 186.

33 Auch Schweitzer teilte diese Ansicht und begründete sie wie Widor mit der klanglichen Einheitlichkeit der Cavaillé-Coll-Orgel. Ein reiches Arsenal aufeinander abgestimmter Grundstimmen und Mixturen ermögliche „die von Bach gedachte klare und gesättigte Klangfarbe [...]. Denn die Bachsche Fuge verlangt Homogenität der Klangfarbe auf allen drei Klavieren! Sie ist einfarbig gedacht, wie der Kupferstich. [...] Darum spielen die französischen Organisten die Bachschen Fugen in manchem einfacher, klarer und sachgemäßer als wir: ihre Orgel steht der Bachschen näher als die unsrige. Wir aber müssen die Bachsche Fuge unserer Orgel anpassen. "Albert Schweitzer, Deutsche und französische Orgelbaukunst und Orgelkunst. Faksimilierter Nachdruck der 1. Auflage von 1906, Wiesbaden 1962, S. $27 \mathrm{ff}$. 
glaubte: „Ce n'est plus le Bach de la fugue que nous invoquons, c'est le mélodiste pathétique, le maître expressif par excellence des Préludes, du Magnificat, de la Messe en Si, des Cantates et de la Passion suivant St. Mathieu.“34 Indem Widor den „pathetischen Melodiker“ und „ausdrucksvollen Meister“ in den Vordergrund rückte, dessen Orgelwerk auf der klangschönen und sinfonischen Cavaillé-Coll-Orgel auf ideale Weise wiedergegeben werden konnte, avancierte er mit seinen eigenen Orgelsinfonien zum natürlichen Nachfolger Bachs $^{35}$ und legitimierte und harmonisierte so die Übertragung einer weltlichen Gattung auf die Orgel ebenso, wie er die Bedeutung der französischen Orgelmusik als patriotisches „Bollwerk" entscheidend beförderte.

\section{Charles-Marie Widors "Symphonies pour orgue“}

Widors zehn Orgelsinfonien sind zwischen 1872 und 1900 entstanden, komponiert in aufsteigender Tonfolge ${ }^{36}$ : c, D, e, f (op. 13), f, g, a, B (op. 42), c (op. 70), D (op. 73). Mehrere Sätze aus op. 13, vor allem die kontrapunktisch angelegten Stücke, dürften schon früher, während Widors Studienzeit entstanden sein. Die frühen Sinfonien bilden jeweils kein kohärentes Ganzes, sondern es handelt sich eher um eine Zusammenstellung von kontrastierenden Einzelstücken im Sinne einer Suite, woraus auch die ungewöhnlich große Zahl an Sätzen von durchschnittlich fünf resultiert. Barocke Formen wie Präludium, Fuge, Toccata und Passacaglia stehen neben romantischen und liedhaften Sätzen in der Tradition des Charakter-, mitunter auch des Salonstücks und tragen Bezeichnungen wie Pastorale, Intermezzo, Marsch, Scherzo oder Cantabile. Größere Formentwicklungen finden in den frühen Orgelsinfonien ebenso wenig statt, wie die Sonatenhauptsatzform an irgendeiner Stelle konsequent angewendet wird. Erst in den mittleren Sinfonien op. 42 finden sich deutlichere Ansätze thematischer Arbeit und formale Aspekte des Sinfonischen, wie zyklische Anlagen durch thematische Verwandtschaft. Besonders im Kopfsatz schafft Widor durch eine reiche Modulatorik größere Entwicklungsbögen mit Elementen der Sonatenhauptsatzform, wobei der Themendualismus

„durch den Gegensatz zweier Prinzipien [ersetzt wird]: Einem fest gefügten, choralartigen Hauptthema folgt unmittelbar ein rhapsodisch ungebundenes Triolenmotiv ohne thematische Qualität. Durchführung und Kombination beider Elemente beschränken sich nicht auf einen abgrenzbaren Formteil, sondern bestimmen den Satz in seiner Gänze und gipfeln in einer grandiosen Wiederkehr des Hauptthemas, das in einen pathetischen Schluß hineinführt. “37

Die spieltechnischen Anforderungen der 5. bis 8. Sinfonie sind erheblich, sowohl hinsichtlich pianistischer Virtuosität als auch in der Pedalbehandlung mit regelmäßiger Ver-

34 „Wir berufen uns nicht länger auf den Bach der Fuge, sondern auf den pathetischen Melodiker, den ausdrucksvollen Meister par excellence der Präludien, des Magnificat, der h-Moll-Messe, der Kantaten und der Matthäus-Passion." Charles-Marie Widor, Vorwort zu Symphonies pour Orgue, Paris 1887, zitiert nach: Ben van Oosten, Charles-Marie Widor. Vater der Orgelsymphonie, Paderborn 1997, S. 270.

35 „Widor hatte sich mit diesen Werken nichts geringeres als die Weiterführung der unterbrochenen Tradition von J. S. Bach zum Ziel gesetzt. Dies war keine Überheblichkeit, wenn man das Niveau und den Geschmack des größeren Teils der damaligen französischen Organisten und des Publikums betrachtet." Van Oosten, Widor, S. 294.

36 Ebenso verfuhr später Louis Vierne mit seinen sechs Orgelsinfonien.

37 Gerhard Blum, Art. Charles-Marie Widor, in: Lexikon der Orgel, Laaber 2007, S. 836. 
wendung des Doppelpedals, das nicht nur harmonische, sondern häufig auch melodische Funktion erfüllt. ${ }^{38}$

Die beiden letzten Sinfonien, die Symphonie Gothique op. 70 (1894) und die Symphonie Romane op. 73 (1899) unterscheiden sich deutlich von den vorherigen Werken dieser Gattung, indem sie mit ihrem spirituellen Anspruch unter Verwendung gregorianischer Themen eine Synthese des konzertanten und liturgischen Stils bilden. Sie spiegeln Widors gewandelte ästhetische Auffassung von einer der Orgel angemessenen Musik wider, die für ihn ohne eine Verbindung zur Gregorianik nicht mehr denkbar war. Die Entwicklung der Widor'schen Orgelsinfonie über einen Zeitraum von fast 30 Jahren beschreibt Albert Schweitzer wie folgt:

„Seine zehn Symphonien stellen die Entwicklung der Orgelkunst, wie er sie an sich erlebt hat, dar. Die ersten sind formvollendete, mehr von lyrisch-melodischem, manchmal sogar sentimentalem Geiste durchwehte Schöpfungen, die aber in der wunderbar großen Struktur der Themen die einzigartig organistische Begabung des Schöpfers zeigen. Mit der fünften Symphonie verläßt er diese Bahn. Das Lyrische tritt zurück; etwas anderes ringt nach Gestaltung. Zunächst noch in melodischer Form, in der fünften und sechsten Symphonie, die zu seinen bekanntesten gehören. Die siebente und achte sind Übergangswerke. Sie sind orgelmäßig und doch gewagt orchestral gedacht. Welch ein Wunderwerk, der erste Satz der achten Symphonie! Zugleich aber tritt das Herbe immer stärker hervor, das Herbe, das Widor dann in den beiden letzten Symphonien zur heiligen Kunst zurückführt. "39

Zumindest für die erste Werkgruppe op. 13 erscheint die Gattungsbezeichnung Orgelsinfonie eher willkürlich bzw. lediglich auf die neuartige, suggestive Klanglichkeit der Cavaillé-Coll-Orgel bezogen.

„Insofern ist es von geringer Bedeutung, wenn Widor als erster den Titel ,Symphonie‘ für Orgelwerke verwendete; die Würdigung als ,Vater der Orgelsymphonie‘ ist angesichts der vielfältigen Wurzeln der Orgelsymphonik simplifizierend oder rein äußerlich in ihrem Bezug auf die bloße Terminologie." 40

Abgesehen davon, dass unter dem Einfluss und in der Nachfolge Widors die Orgelsinfonie bis ins zweite Jahrzehnt des 20. Jahrhunderts hinein zur dominierenden Gattung in der französischen Orgelliteratur wurde und von daher die „Würdigung als ,Vater der Orgelsymphonie“ “ ihre Berechtigung hat, ${ }^{41}$ ist es im Kontext des Strebens nach einer eigenständigen nationalen Musikkultur einerseits und angesichts der Skepsis, die dem Titel „Orgelsinfonie“ auch in Frankreich entgegengebracht wurde, andererseits, durchaus bedeutungsvoll,

38 „Man könnte sagen, daß bezüglich des Aufführungsstils, instrumentaler Technik und idiomatischen Schreibstils, Widor für die Orgel bedeutet, was Komponisten wie Chopin und Liszt für das Klavier oder Paganini für die Geige bedeuteten. Dank Widor entwickelte sich eine spezielle Orgeltechnik, die mit dem grundlegenden Charakter des Instrumentes in Einklang steht. Widors Orgelwerke erfordern eine völlige spieltechnische Beherrschung des Instrumentes und bilden einen Prüfstein für Organisten." Van Oosten, Widor, S. 296ff.

39 Schweitzer, Deutsche und französische Orgelbaukunst, S. 45.

40 Gerhard Blum, Art. Symphonie, in: Lexikon der Orgel, S. 759.

$41 \mathrm{Zu}$ nennen sind insbesondere die sechs Orgelsinfonien von Louis Vierne (1870-1937), mit denen er in der formalen Gestaltung, dem weitgehenden Verzicht auf polyphone Techniken und diversen Details, wie der Komposition in aufsteigender Tonfolge, deutlich an die Vorlagen seines Lehrers Widor anknüpft, auch wenn er, bei gleichzeitiger Orientierung am traditionellen Sonatenhauptsatz, harmonisch mit der Einbeziehung der Ganztonleiter und übermäßiger Akkorde neue harmonische Wege geht. 
dass Widor nicht allein als erster, sondern überhaupt diesen Gattungsbegriff verwendete. Seine Entscheidung zeugt von Mut und Vertrauen in die eigenen kompositorischen Möglichkeiten, gepaart mit einem gehörigen Sendungsbewusstsein. Alexandre Guilmant etwa blieb bei seinen ungefähr zeitgleich entstandenen mehrsätzigen Orgelwerken, die von der Struktur und Satzfolge her „sinfonischer“ sind als Widors Orgelsinfonien, bei der Bezeichnung Sonate. Offenbar widersprach es seinem, wie auch César Francks ästhetischem Empfinden, einen so eng mit Orchestermusik assoziierten Gattungsbegriff auf die Orgel zu übertragen. ${ }^{42}$ Widor dagegen scheint die Größe und Bedeutungsschwere des Begriffs gerade als angemessen empfunden zu haben, um die Erhabenheit und Majestät seiner auf die Cavaillé-Coll-Orgel kongenial zugeschnittenen Musik und das hehre Ziel der „Weiterführung der unterbrochenen Tradition von J. S. Bach “ ${ }^{“ 3}$ zum Ausdruck zu bringen.

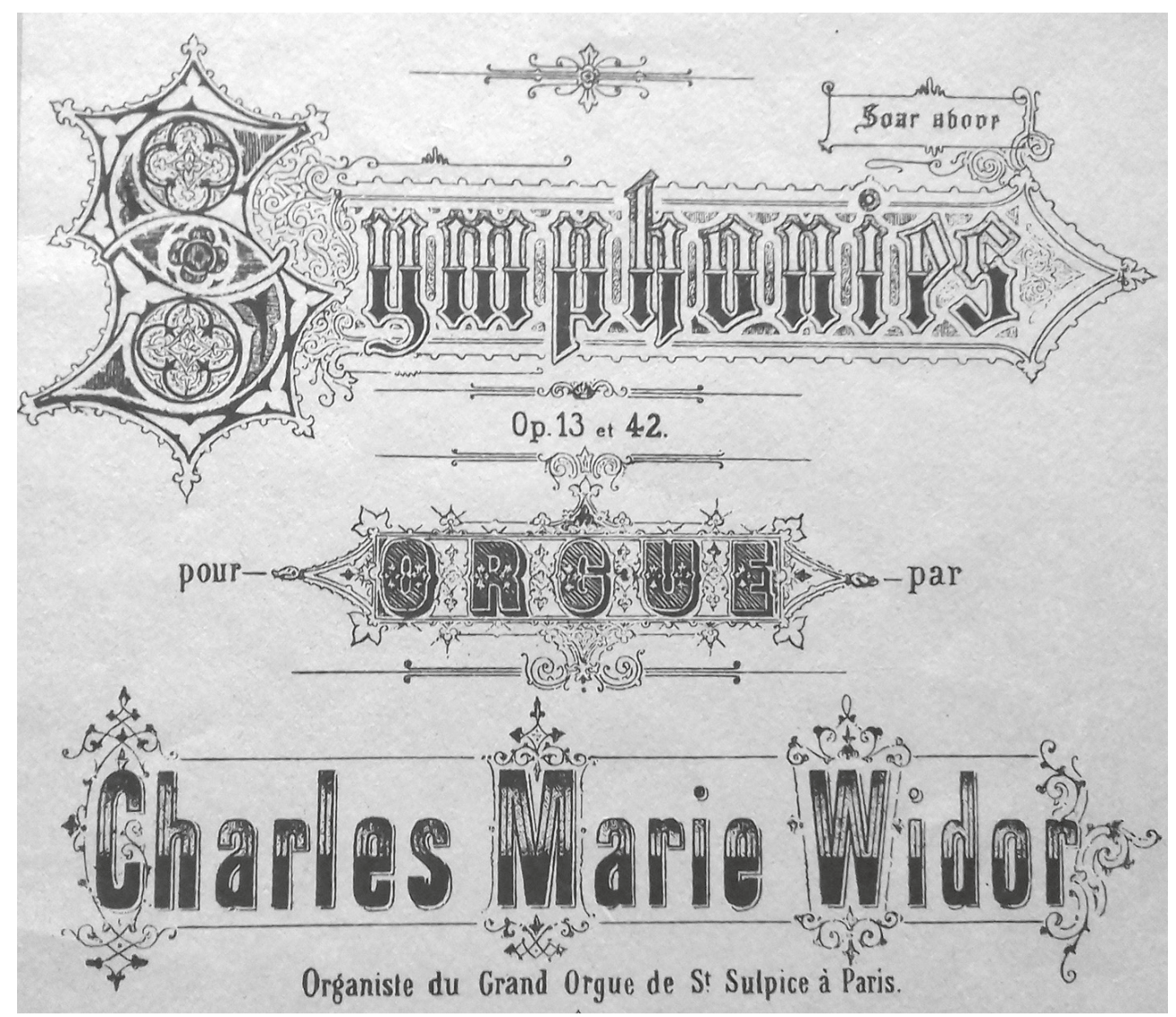

Titelblatt der Symphonie pour orgue mit dem Motto ,soar above‘ (siehe Anm. 43)

42 Das belegt auch die Bearbeitung seiner 1. und 8. Orgelsonate für Orgel und Orchester: Beide Male wählte Guilmant die Bezeichnung „Sinfonie“, ohne substantielle Veränderungen vorzunehmen.

43 Van Oosten, Widor, S. 294. Darauf deutet auch die selbstbewusste Devise „soar above“ (aufwärtssteigen), die er auf dem Titelblatt der Erstausgabe von op. 13 (1872) anbringen ließ, wohl als sinnreiche Anspielung auf seine Herkunft: Über seine Mutter stammte Widor von den Gebrüdern Montgolfier ab, die 1783 den ersten Heißluftballon aufsteigen ließen. 
Gleichzeitig gab er sich alle Mühe, seine Titelwahl zu verteidigen, indem er eine deutliche Unterscheidung zwischen Orchester- und Orgelsinfonie vornahm. Er verwahrte sich gegen den Vorwurf, die Orgel als Orchesterersatz zu benutzen. Seiner Ansicht nach war die Orgelästhetik mit ihrem Tonfarbenreichtum einerseits und statischen Klang andererseits nicht vergleichbar mit den Ausdrucksmöglichkeiten und der variablen Klanglichkeit des Orchesters. Folglich waren für ihn Orgelarrangements von Orchestermusik der „Gipfel der Geschmacklosigkeit; nie wird die seelenlose, unpersönliche Orgelpfeife den warmen, ausdrucksvollen Ton der Streicher auch nur anzudeuten vermögen! ‘44 Der Versuch, die Orgel als Orchesterersatz zu benutzen, entstelle „das wahre Wesen des Instruments und mach[e] aus ihm ein gefälschtes Orchester, wie die unbeholfenen und schwerfälligen Transkriptionen von Symphoniensätzen, Ouverturen, Märschen und Suiten zur Genüge “45 bewiesen.

Indem Widor sich mit seinen Orgelsinfonien von Übertragungen der Orchestermusik auf die Orgel distanzierte, machte er zugleich deutlich, dass sie für ihn keine Profanierung der Orgel und Orgelmusik darstellten. So wie César Franck sich trotz des sinfonischen Ansatzes in seinem Orgelwerk und der bewussten Verwendung von Gattungsbezeichnungen und Titeln aus dem Bereich weltlicher Musik dennoch nicht als säkularer Orgelkomponist verstand und vor allem von seinen Schülern im Gegenteil als sakraler Komponist und Gallionsfigur einer neuen religiösen Ästhetik propagiert wurde, so wollte auch Widor seine Orgelsinfonien als durchaus religiöse Musik verstanden wissen. Ein äußeres, gleichwohl aussagekräftiges Anzeichen dafür war, dass er während der Messe, d. h. in den Pausen zwischen den liturgischen Handlungen und insbesondere als Nachspiel, selbst regelmäßig Sätze aus seinen Sinfonien spielte, seine konzertant-virtuose Orgelmusik also durchaus als „Kirchenmusik“ ansah, ohne liturgische Funktion zwar, aber im Sinne einer dem Kirchenraum und Instrument angemessenen Musik. Im Gegensatz zu Franck, der mit Aussagen über seine Musik und seine kompositorischen Intentionen und Beweggründe äußerst sparsam umging, meldete sich Widor in seinen Erinnerungen, in Vorworten, Essays und zahlreichen überlieferten Aussagen ausführlich zu Wort, wobei er sich auch zur Frage des religiösen Gehalts seiner Orgelsinfonien und konzertanter Orgelmusik überhaupt äußerte. Demnach betrachtete er den Orgelklang als solchen für dazu prädestiniert, religiöse Gefühle wachzurufen: „Sie [die Orgel] allein vermag in unbeschränkter Dauer ohne dynamische Schwankungen zu erklingen und aus dem unbestimmten Gefühl des Unendlichen heraus die in jeder Brust schlummernden Gedanken des Ewigen und der Gottesverehrung wachzurufen. ${ }^{\star 46}$ Gegenüber Albert Schweitzer äußerte er seine Überzeugung, die Orgel werde „ihrem Wesen und ihrem Ort entfremdet [...], sobald sie nur Ausdruck des subjektiven Geistes ist. “ 47 Orgelspielen heiße, „einen mit dem Schauen der Ewigkeit erfüllten Willen manifestieren. [...] Dieser Wille des Organisten, der sich in der Orgel objektiviert, soll den Hörer überwältigen “ ${ }^{48}$, so dass dieser gewissermaßen dazu gezwungen werde, sich dem unendlichen Geist zu öffnen. Es war also vor allem der religiöse Aspekt der Unendlichkeit, der Majestät und objektiven Erhabenheit, der die Orgel für Widor zu einem sakralen Instrument und seine Sinfonien zu sakraler Musik machte, eine Einstellung, die sich harmonisch in die spezifisch französische Hinwendung zur Sinfonie fügte: Erhabenheit und Monumentalität als zentrale Merkmale des Sinfonischen ließen sich bruchlos auf die Orgel

44 Widor, Vorrede zu Rupp, Orgelbaukunst, S. XII.

45 Widor, Die Technik des modernen Orchesters, S. 191.

46 Widor, Vorrede zu Rupp, Orgelbaukunst, S. XII.

47 Schweitzer, Deutsche und französische Orgelbaukunst, S. 39.

48 Ebd., S. 38. 
übertragen und begünstigten eine Verwischung oder gar Aufhebung der Grenzen zwischen Profanität und Sakralität. In Widors Orgelsinfonien stehen sich Profanität und Sakralität nicht mehr unversöhnlich gegenüber, sondern verbinden sich zu einer Art Synthese, die deshalb möglich ist, weil das Sinfonische bei Widor nicht auf formalen und strukturellen Merkmalen basiert, sondern auf zeitlicher, klanglicher und dynamischer Monumentalität, zu der der Komponist in erster Linie durch die gewaltige Kathedrale St. Sulpice und die sich perfekt in sie einfügende Orgel inspiriert wurde. ${ }^{49}$ Auch in Widors Orgelstil sind beide Pole vorhanden: sakrale Erhabenheit, Seriosität und eine gewisse intellektuelle Strenge auf der einen Seite, profane Eleganz, mitreißende Rhythmik und ein ausgeprägter Sinn für Effekte auf der anderen Seite. ${ }^{50}$

\section{Die deutsche Tradition: Orgelsinfonik ohne Orgelsinfonie}

So wie sich in der französischen Orgelsinfonik, repräsentativ ausgeprägt in den Orgelsinfonien Widors und seiner Schüler, Aspekte des Sinfonischen mit nationalen und nationalistischen Tendenzen in der französischen Musikästhetik verbanden, wodurch nicht nur die Entstehung dieser neuartigen Gattung möglich wurde, sondern worin auch das Geheimnis ihres Erfolgs lag, spiegelt auch der Umgang mit dem Sinfonischen in der deutschen konzertanten Orgelmusik seit der zweiten Jahrhunderthälfte spezifisch nationale musikästhetische und gattungsgeschichtliche Voraussetzungen wider, die jedoch zu einem konträren Ergebnis führten: Obwohl bereits für die seit 1850 entstandenen großen Orgelwerke Franz Liszts mit ihrer neuartigen virtuosen Anlage und zeitlichen Ausdehnung sowie mit der Übertragung des zyklischen Prinzips auf die Orgel und einige Jahrzehnte später für die großen Orgelwerke Regers, von den Choralfantasien bis zu den Sonaten, die als sinfonische Aspekte nicht nur Monumentalität, sondern auch eine ausgeprägte motivische Arbeit aufweisen, die Bezeichnung Orgelsinfonik im Sinne der Begriffs- und Gattungsdefinition angemessener erscheint als in der konzertanten französischen Orgelmusik, findet sich der Gattungsbegriff Orgelsinfonie weder bei Liszt noch bei Reger oder anderen Orgelschaffenden ihres jeweiligen Umfeldes. ${ }^{51}$

49 Es überrascht nicht, dass Widors 7. und 8. Sinfonie aufgrund ihrer monumentalen Länge und Schwierigkeit als die orchestralsten, mithin sinfonischsten unter seinen acht Orgelsinfonien galten und gelten. Widor selbst beendete danach für Jahrzehnte sein Schaffen in dieser Gattung, da er mit ihnen nach eigenem Bekunden die kompositorischen und klanglichen Möglichkeiten der sinfonischen Orgel ausgeschöpft hatte. Van Oosten, Widor, S. 315.

50 Dieser Stil wurde als Äquivalent zu Widors Persönlichkeit gesehen: „Einerseits der Künstler, wissend, streng, kalt; andererseits der Weltmann, lächelnd, sprachgewandt, mit einer etwas herkömmlichen Freundlichkeit, beide zeigen sich abwechselnd und manchmal gleichzeitig in seiner Musik." Ebd., S. 313.

51 Aus Liszts Schülerkreis ist hier vor allem Julius Reubke (1834-1858) zu nennen, dessen Sonate Der 94. Psalm (1857) sowohl bezüglich der Aufhebung der klassischen Mehrsätzigkeit und monothematischen Durchführung als auch im Hinblick auf ihre zeitliche Ausdehnung und den virtuosen Gestus direkt auf das Vorbild Liszts verweist. Zu erwähnen ist aber auch der ebenfalls in Weimar wirkende Stadtkirchenorganist Johann Gottlob Töpfer (1791-1870), dessen drei Choralfantasien aus dem Jahr 1859 großangelegte Werke sinfonischen Formats sind (Töpfer selbst bezeichnete sie als „Konzert-Fantasien“) und die mit der Idee der Steigerungsfuge als einer Verbindung aus dem Prinzip der Fuge und sinfonischen Steigerungsformen sowie der kontrapunktischen Bearbeitung der Choralmelodien eine direkte Brücke zu Regers Choralfantasien bilden. In Regers Umfeld war es vor allem Sigfrid Karg-Elert (18771933), der lange Zeit in direkter Konkurrenz zu Reger dessen Formideen in eigenen Orgelkompositio- 
Eine Ursache für das Vermeiden dieser Bezeichnung dürfte das sich in einer ungebrochenen sinfonischen Tradition herausgebildete „Reinheitsgebot“ der Sinfonie als einem durch und durch deutschen Phänomen sein. Im 19. Jahrhundert war es in erheblichem Maße auch ein Phänomen von nationaler Tragweite, das dazu beitrug, die fehlende staatliche Einheit zu kompensieren und eine nationale Identität zu stiften. Die deutsche $\mathrm{Mu}-$ sikauffassung wird im 19. Jahrhundert von dem nationalen oder vielmehr nationalistischen Gedanken geleitet, dass die Sinfonie als Gattung eine deutsche Errungenschaft und zugleich die höchste Gattung von allumfassender Größe sei. So heißt es beispielsweise bei dem deutschen Musikkritiker und -schriftsteller Otto Gumprecht:

„Geraume Zeit hatte die Musik theils an der Kirche, theils an der Bühne sich emporgerankt, ehe sie zum klaren Bewußtsein ihrer Macht gelangte. Als selbständige, ihren Schwestern ebenbürtige Kunst fühlte sie sich erst mit dem Augenblick, da sie begann, in die großen instrumentalen Formen ihr Wesen zu ergießen. Der Abschluß, welchen sie sich auf solche Weise gab, war aber das Werk desjenigen Volks, das vor allen andern dazu berufen worden, seine unerschöpfliche Innerlichkeit in der Sprache der Töne zu offenbaren. Unsere classische Instrumentalmusik ist ein echtes Kind des deutschen Geistes. [...] Während in Italien und Frankreich fast die gesammte musikalische Production dem Gesange zugute kam, vertiefte sich das deutsche Gemüth mit Vorliebe in die räthselvolle Welt der Instrumente." ${ }^{52}$

Vokalmusik wird hier als Vorstufe zur „absoluten“ Musik angesehen, die unabhängig von im geschriebenen Wort sich manifestierenden theologischen oder dramatischen Inhalten allein durch die metaphysische und rätselhafte "Sprache der Töne“ spricht und dabei ihre eigentliche „Macht“ entfaltet. Musik als Machtinstrument also, das in religiöser Überhöhung qua Berufung dem deutschen Volk übertragen wurde. Das Rätselhafte, Metaphysische, Unergründliche als Begründung für die Überlegenheit der reinen Instrumentalmusik findet sich bereits vor der Entstehung von Beethovens Sinfonien in der romantischen Musikästhetik um 1800. So heißt es 1799 in Wilhelm Heinrich Wackenroders Phantasien über die Kunst:

„In der Instrumentalmusik [...] ist die Kunst unabhängig und frey, sie schreibt sich nur selbst ihre Gesetze vor, sie phantasirt spielend und ohne Zweck, und doch erfüllt und erreicht sie den höchsten, sie folgt ganz ihren dunkeln [sic!] Trieben und drückt das Tiefste, das Wunderbarste mit ihren Tändeleyen aus. [...] der höchste Sieg, der schönste Preis der Instrumente sind die Symphonien; [...] denn sie enthüllen in räthselhafter Sprache das Räthselhafteste, sie hängen von keinen Gesetzen der Wahrscheinlichkeit ab, sie brauchen

nen aufgriff und auch das Adjektiv „sinfonisch“ in Werktiteln (Drei sinfonische Kanzonen op. 85 und Drei symphonische Choräle op. 87) verwendete. Karg-Elert ist der einzige deutsche Orgelkomponist, der einer seiner letzten großen Kompositionen für Orgel den Titel „Sinfonie“ gab, sogar unter Verzicht auf den Zusatz „für Orgel“: Es handelt sich um die Sinfonie fis-Moll op. 143 aus dem Jahr 1930, ein über 30-minütiges, monumentales Werk, das wohl vor allem aufgrund seiner großformalen Anlage mit vier charakteristischen Sinfonie-Sätzen (Allegro - Scherzo - Largo - Vivace, samt Introduktion, Choral und Coda) die Gattungsbezeichnung Sinfonie trägt.

52 Otto Gumprecht, Musikalische Charakterbilder: Schubert, Mendelssohn, Weber, Rossini, Auber, Meyerbeer, Leipzig 1869, S. 29 f. 
sich an keine Geschichte und an keine Charakter [sic!] zu schließen, sie bleiben in ihrer rein poetischen Welt. “53

Die romantische Sehnsucht nach dem Unendlichen, Geheimnisvollen und Unaussprechlichen erfüllte sich also in der Fähigkeit der Instrumentalmusik und insbesondere der Sinfonie, das Unsagbare auszudrücken. Mit Beethovens Sinfonien verbreitete sich die romantische Idee von der „Macht" der reinen Instrumentalmusik und damit der „deutschen“ Musik. Das „Reinheitsgebot“ der Sinfonie spielte im Kontext ihres „Machterhalts“ eine zentrale Rolle, und „Übertretungen“, vor allem durch Einbeziehung des Wortes, wurden, angefangen bei Beethovens Neunter, im musikästhetischen Diskurs stets mit Ablehnung, zumindest aber mit einiger Irritation aufgenommen. ${ }^{54}$ Das zweifache Paradoxon des Kompositums „Orgel-Sinfonie“ durch die Zuweisung einer weltlichen Gattung an ein genuin sakrales Instrument und d e r Orchestergattung an ein solistisches Tasteninstrument konnte im deutschen Musikdiskurs mit seinem Hegemonialanspruch bezüglich der Instrumentalmusik und der Sinfonie einerseits und dem protestantisch-nationalistischen Beharren auf der Orgel als kirchlich-funktionalem Instrument andererseits nur Ablehnung hervorrufen.

Auch Max Reger lehnte „Anleihen“ der konzertanten Orgelmusik aus dem Bereich weltlicher Instrumentalmusik ab. Dort, wo er - selten genug - Gattungsbezeichnungen wie Sonate oder Suite entlehnte, legte er Wert darauf festzustellen, dass es sich dabei nicht um Gattungsübertragungen im engeren Sinne handelte. So schreibt er zu seiner Sonate fisMoll an den Berliner Organisten Arthur Egidi: „Eine neue Sonate (Fis-Moll) für Orgel ist fertig. Erschrecken Sie nicht über den Titel ,Sonate; es ist keine Sonatenform. Der Titel ist hier nur Kollektivtitel [...]." ${ }^{55}$ Auch das Adjektiv sinfonisch, das er ein einziges Mal, näm-

53 Wilhelm Heinrich Wackenroder, Phantasien über die Kunst, für Freunde der Kunst, hrsg. von Ludwig Tieck, Hamburg 1799, S. $261 \mathrm{ff}$.

54 Das Finale der Neunten wurde vielfach als Schwachpunkt des Werkes angesehen. So heißt es 1825 in der Allgemeinen Musikalischen Zeitung: „Es ist nicht zu läugnen, dass diess Finale mit seinen Chören der schwächere Theil des genialen Werks ist." $A M Z 27$ (1825), Sp. 447. Die Verständnislosigkeit des Rezensenten gipfelt in der ironischen Bemerkung, auf Beethoven treffe zu, „was man von Händel gesagt hat: Auch in der Verirrung - gross!“ Ebd. Die ganze Sinfonie wurde als „höchst merkwürdige Verirrung des durch seine gänzliche Gehörlosigkeit unglücklich gewordenen, nun erlöseten [sic!] Mannes“ bezeichnet. $A M Z 30$ (1828), Sp. 246. Auch lange nachdem sich Beethovens 9. Sinfonie durchgesetzt hatte, blieb das deutsche Unbehagen gegenüber dem vokalen Abschluss einer Sinfonie bestehen. So heißt es in Ferdinand Hands Ästhetik der Tonkunst: „Nach einem colossalen Instrumentalwerk kann eine vierstimmige Cantate mit Soli nur kleinlich und zufällig erscheinen; eine Steigerung des Effects wird, nachdem der letzte Instrumentalsatz alle Kräfte aufgeboten hat, nicht möglich, und nichts bleibt übrig als der Contrast. [...] Abgesehen von Beethoven's großartiger und längst durch Bewunderung belohnter Leistung wird die zur Verbindung des Gesangs gewählte Form einer [an eine Sinfonie] angeschlossenen Cantate Allgemeingültigkeit nicht gewinnen können." Ferdinand Hand, Aesthetik der Tonkunst, Zweiter Theil, Leipzig 1847, S. 419.

55 Brief Max Regers an den Berliner Organisten Arthur Egidi (1859-1943) vom 8.4.1899, zitiert nach: Hermann J. Busch, Verzeichnis der Orgelwerke Max Regers, in: Ders. (Hrsg.), Zur Interpretation der Orgelwerke Max Regers, Kassel 1988, S. 72-103; hier S. 78. An Karl Wolfrum (1856-1937), der sich etwa zeitgleich mit der Komposition von Orgelsonaten beschäftigte, schreibt er: „Nachdem ich als Op. 52 nun drei Phantasien für Orgel vollendet habe [...], werde nun nächstens wieder an die Sonate gehen, obwohl ja die Sonatenform an und für sich eigentlich für die Orgel nicht verwendbar ist! Unsere Orgelsonaten sind doch mehr Suiten!" Ohne Datum zitiert bei: Adalbert Lindner, Max Reger. Ein Bild seines Jugendlebens und künstlerischen Werdens (1922), 3. erweiterte und ergänzte Auflage, Regensburg 1938, S. 204, Anm.12. 
lich für die Symphonische Fantasie und Fuge op. 57 verwendete, deutet nach Überlieferung durch seinen Lieblingsinterpreten Karl Straube (1873-1950)

„nicht in die Richtung der symphonischen Dichtung oder Orgelsymphonie, sondern will auf die Ausdrucksgewalt der musikalischen Großform - und da ist die Fuge mit eingeschlossen! - hinweisen. Nach Straubes Meinung haben sowohl die dreiteilige Phantasie (die noch entfernt an die klassische Sonatenform mit ihren zwei Themen, der Durchführung und der regelrechten Reprise erinnert) als auch die große Doppelfuge durch ihre vierteilige Form die Bezeichnung ,symphonisch'veranlaßt." 56

In der Regel meinen Werk- und Satzbezeichnungen aus dem Bereich der Sonate und sinfonischen Instrumentalmusik bei Reger „nichts Konkretes, sondern [sie] beschwör[en] allgemein das Großartige, Allumfassende eines symphonischen Anspruchs im Sinne Beethovens“. 57 Reger war grundsätzlich skeptisch gegenüber den Möglichkeiten der Übertragung der Sonatensatzform auf die Orgel, insbesondere was lyrische und liedhafte Seitenthemen und Sätze betraf, die er mit ihrem Ausdruck subjektiven Empfindens als der Orgel nicht angemessen erachtete. Vielmehr sei auf der Orgel „wohl stets nur mit den rein orgelgemäßen Formen der freien Phantasie, der Variation, Fuge, Passacaglia und mit Verwendung des geistlichen Liedes und des Chorals auszukommen "58. Er sah die Gefahr einer Verflachung „durch irgendwelches Zugeständnis an die hypermoderne Weichlichkeit und Sentimentalität“ und wollte unbedingt den „weltlich sentimentale[n] Augenaufschlag und dieses frömmelnde Hinüberneigen ins geistliche Gebiet" vermeiden. ${ }^{59}$ Mit dieser Haltung bewegte sich Reger, obwohl selbst überzeugter Katholik, im typisch deutsch-protestantischen Beharren auf Kontrapunkt und Choral als der einzigen wirklich orgelmäßigen formal-strukturellen und geistigen Grundlage der Orgelkomposition.

Andererseits tragen alle großen Orgelwerke Regers, und das betrifft auch die Choralfantasien, nicht nur wegen ihrer zeitlichen, formalen und klanglichen Monumentalität, sondern auch aufgrund ihrer „symphonischen Durchstrukturierung des am spätromantischen Orchester orientierten Orgelsatzes" 60 und der intensiven motivischen Arbeit sinfonische Züge. Vor allem die großen Weidener Orgelwerke, zu denen auch op. 57 gehört, weisen eine starke Affinität zum Sinfonischen auf:

„Formale Einheit bei gleichzeitiger extremer Vielfalt der motivischen Gestalten und Satzcharaktere, Finalformen mit apotheotischen Schlüssen, die Bestimmung für das öffentliche Konzert, der ,große Stil', der sich im virtuosen Anspruch ebenso ausdrückt wie in der monumentalen Gestaltungsart, die rhetorische Schlagkraft, die enorme Ausdehnung, die Übersteigerung des inhaltlichen und ästhetischen Anspruchs - dies alles sind Charakteristika der

56 Heinz Wunderlich, „Karl Straubes Vortragsbezeichnungen in der Symphonischen Fantasie und Fuge op. 57“, in: Hermann J. Busch (Hrsg.), Zur Interpretation der Orgelwerke Max Regers, Kassel 1988, S. 64-71; hier S. 65.

57 Blum, Art. Symphonie, S. 760.

58 Lindner, Max Reger, S. 203.

59 Ebd., S. 204. „In allen nachbachischen Orgelwerken, wenige Ausnahmen abgerechnet, fand Reger eben nicht genügend Bachsches ,Rückgrat' [und sah in ihnen] nichts anderes als eine fortschreitende Verflachung und Verweichlichung des Orgelstiles, so daß er für die meisten derartigen mit ihm am Flügel durchgegangenen Werke nichts übrig hatte als den Namen ,Salonorgelstil'“. Ebd., S. 177.

60 Andreas Jacob, Art. Max Reger, in: Lexikon der Orgel, S. 626. 
Weidener Orgelwerke und erzeugen den symphonischen Duktus. In diesem Sinn haben letztlich alle großangelegten Orgelwerke Regers teil am Begriff des Symphonischen. "61

\section{Das Sinfonische in Max Regers "Symphonische Phantasie und Fuge“ op. 57}

In Symphonische Phantasie und Fuge op. 57 orientiert sich Reger deutlich an der Sonatenform, sowohl im Verhältnis der Sätze zueinander, als auch innerhalb der einzelnen Formteile. Die Fantasie besteht aus drei klar voneinander abgegrenzten Teilen, wobei der erste als Exposition und Durchführung definiert werden kann und der dritte, thematisch auf ihn bezogene Teil als Reprise. Gleichzeitig lässt sich zusammen mit dem kantablen Mittelteil das Verhältnis der drei Formteile zueinander als dreisätziger Sonatenzyklus beschreiben. Auch die Fuge ist formal wie eine viersätzige Sonate oder Sinfonie aufgebaut: Sie besteht aus einem ersten schnellen, einem langsamen, einem scherzoartigen dritten Teil und einem bewegten Finale. Eine Verbindung zur Fantasie wird sowohl auf thematischer Ebene hergestellt - das Hauptthema der Fuge ist aus dem dritten Thema der Fantasie, dem sogenannten „Abstiegsmotiv“, abgeleitet - als auch durch das Prinzip des Dualismus, das einerseits die Themen innerhalb der einzelnen Formteile, andererseits das Verhältnis von Fantasie und Fuge zueinander charakterisiert: Die Themen sind kontrastreich gestaltet in dem für Reger typischen Wechsel zwischen vorwärtsdrängender, „hyperdramatischer“62 Intensität und ruhiger, melancholischer Entrücktheit. Der Gestus der Fantasie ist frei, von einer subjektiven und expressiven Grundstimmung getragen; die Fuge dagegen bei aller klanglichen Fülle von kontrapunktischer Strenge.

Reger bedient sich in seinem Opus 57 also ganz bewusst der von Liszt geprägten mehrdeutigen Sonatenform mit ihrem Prinzip der Mehrsätzigkeit in der Einsätzigkeit, das um 1900 längst „prototypisch-klassische Gültigkeit“63 besaß. Doch nicht nur auf formaler Ebene, sondern auch hinsichtlich der Programmatik bzw. des semantischen Gehalts verweist das Werk auf Liszts Idee des Sinfonischen, das er in der Gattung der Sinfonischen Dichtung mit programmatischen Inhalten verknüpfte. Entgegen der durch seinen Schüler Heinz Wunderlich überlieferten Aussage Straubes, das Adjektiv „symphonisch“ im Titel von op. 57 weise „nicht in die Richtung der symphonischen Dichtung oder Orgelsym-

61 Burkhard Meischein, „Dantes ,Inferno“ im symphonischen Gewand der Orgel. Max Regers ,Symphonische Phantasie` opus 57“, in: Organ. Journal für die Orgel 4/1998, S. 15-19; hier S. 18. Reger war sich bewusst, dass seine hoch virtuosen, damals vielfach als unspielbar geltenden und jeden gottesdienstlichen Rahmen sprengenden Orgelwerke eines konzertant-weltlichen Aufführungskontextes bedurften. An den aus Weiden stammenden Musikprofessor Anton Gloetzner (1850-1928) schreibt er am 25.1.1900: „Ich verlange eben einen technisch ausgezeichneten Orgelspieler, einen geistvollen Interpreten u. eine sehr große, moderne Orgel! (3 Manuale) [...] Ich behandle eben die Orgel durchaus als Konzertinstrument. Mit dem Kirchlichen hat's seine Sachen. "Zitiert nach: Dominik Axtmann, „Ausbildung und Stellenwert der Kirchenmusiker beider Konfessionen um 1900“, in: Reger-Studien 9. Konfession - Werk - Interpretation. Kongressbericht Mainz 2012 (= Schriftenreihe des Max-RegerInstituts Karlsruhe XXIII), hrsg. von Jürgen Schaarwächter, Stuttgart 2013, S. 91-120; hier S. 91. Gemeint ist mit Letzterem das niedrige Niveau katholischer Organisten und das Unverständnis kirchlicher Institutionen gegenüber seiner Musik, das er mehrfach beklagt, dabei hoffend, dass „nach und nach der Welt schon wieder zum Bewusstsein kommen [wird], was die Orgel eigentlich ist - nämlich ein Konzertinstrument ersten Ranges!“ Zitiert nach: Ebd., S. 93.

62 Meischein, „Dantes ,Inferno“ im symphonischen Gewand der Orgel“, S. 15.

63 Ebd., S. 16. 
phonie“, sondern lediglich „auf die Ausdrucksgewalt der musikalischen Großform“ “64, hat Reger brieflich mehrfach auf Dantes Inferno aus der Göttlichen Komödie als Inspirationsquelle hingewiesen, dabei jedoch betont, dass ihm keine „spezielle Szenerie, sondern der allgemeine Gefühlsinhalt" 65 der Dichtung vor Augen gestanden habe. Damit vermied er es, sich in den um 1900 noch sehr lebendigen Parteienstreit zwischen den „Neudeutschen“ und den „Konservativen“ einzuschalten und eindeutig Position zur Programmmusik zu beziehen. Lieber zog er sich hinter das zurück, was die ihm wohlgesonnenen Interpreten und Musikschreibenden aus seinen spärlichen Angaben und Andeutungen machten. So schreibt er an Gustav Beckmann (1865-1939), Organist an der Kreuzkirche in Essen und Widmungsträger der Phantasie: „Opus 57 ist angeregt durch Dantes ,Inferno! Das dürfte Ihnen wohl alles Wissenswerte sagen; Opus 57 ist wohl das schwierigste meiner bisherigen Orgelwerke. Mehr kann ich Ihnen darüber nicht sagen, da es mir widerstrebt, ,Programme zu meinen Sachen zu liefern [...]."66 Dagegen benannte Straube explizit einige Strophen aus Dantes Inferno, wie „,Weh euch, verworfne Seelen, wehe! Nicht hoffet je zu sehn das Paradeis. Hinüber bring ich euch zum Strande in ew'ge Finsternis und Eis', [die] ihn [Reger] immer wieder beschäftigt und zu dieser Komposition geführt" hätten. ${ }^{67}$ Burkhard Meischein sieht in der uneindeutigen Positionierung Regers zur Programmmusik bei gleichzeitiger unüberhörbarer Annäherung in der Symphonischen Phantasie eine Strategie des jungen Komponisten, sein Anliegen der Modernisierung der Orgelmusik und der Emanzipation der Orgel als gleichberechtigtem Konzertinstrument zu befördern, ohne in den Richtungsstreit um den Stellenwert der Programmmusik hineingezogen zu werden und ohne sich der Kritik der konservativen Organisten auszusetzen:

„Mit dieser Komposition entzog er sich im Richtungsstreit um die Neudeutsche Schule dem Vorwurf epigonalen Parteigängertums, indem er jene Annäherung eben nicht mit Orche-

64 Wunderlich, „Karl Straubes Vortragsbezeichnungen“, S. 65.

65 Musikalisches Wochenblatt 37 (1906), S. 676. Diese Beteuerung Regers hindert den Autor, Roderich von Mojsisovics, jedoch nicht an einer durchaus programmatischen Interpretation des Werkes: „Die Schrecken der Unterwelt malt der Komponist mit realistischen Farben. Die in jagender Geschwindigkeit einherbrausenden dissonierenden Klänge [...] schildern in nervenerschütternder Treue die furchtbaren Mächte der Finsternis. Inzwischen eingestreut, adagissimo und pianissimo, huschen, den Schatten Verstorbener gleich, frappierende Tongebilde in schemenhafter Zartheit an uns vorüber. Wir werden an Vergil, den Dichter der ,Aeneis', erinnert, auch Beatricens Figur taucht vor unserem geistigen Auge auf." Ebd.

66 Brief vom 18.8.1904, zitiert nach: Hermann J. Busch, „Verzeichnis der Orgelwerke Max Regers“, in: Zur Interpretation der Orgelwerke Max Regers, S. 72-103, hier S. 83.

67 Wunderlich, „Karl Straubes Vortragsbezeichnungen“, S. 65. Dass Wunderlich in der Rückschau dennoch darauf beharrt, es „wäre fehl am Platze, nun in dieser Komposition Programmusik im Sinne der Neudeutschen Schule zu vermuten“ (ebd.), ist weniger ein Beleg für Regers Haltung gegenüber Programmmusik als vielmehr für die seit den 1920er Jahren in der deutschen Musikästhetik verbreitete Ablehnung derselben als minderwertig. Ein ähnliches Werturteil ist auch in dem Verweis auf die „Orgelsymphonie“ enthalten, in deren Richtung op. 57 ebenso wenig weise wie in diejenige der „symphonischen Dichtung". In seiner Biographie des jungen Reger betont Adalbert Lindner ebenfalls die „unbeirrte“ Treue des Komponisten zum „Gotte der absoluten Musik“. Bei aller Anerkennung der programmatischen Werke von Richard Strauss sei Reger „mit der Richtung selbst [...] im Grunde nicht einverstanden“" gewesen. „Sie schien ihm, dem ,absoluten“ Musiker, um dessentwillen unannehmbar, weil er sie nur als ,gemischte' Kunstform, deren Gestaltungsprinzipien nicht rein musikalischer Natur sind, anzuerkennen vermochte und weil er von ihrer Weiterentwicklung leicht eine Abirrung in Bahnen befürchtete, die die Musik in ein zu starkes Abhängigkeitsverhältnis zu andern künstlerischen Faktoren bringen könnte." Lindner, Max Reger, S. $188 \mathrm{f}$. 
stermusik, sondern im symphonischen Gewand der Orgel vollzog und damit in einer Weise verschleierte, die ,programmatisches' Gedankengut erst gar nicht vermuten ließ. Reger hatte es somit nicht nur glänzend verstanden, vornehmlich mit seinen Orgelwerken zu reüssieren, sondern zudem die ideologischen Vor(ur)teile geschickt zu instrumentalisieren, die das scheinbar unverfängliche, in Wahrheit gleichwohl symphonischste, aller Instrumente ihm bot, um - unerkannt - symphonisch-programmatische Musik größten Stils zu schreiben."68

Reger wahrte mit dieser „Erfolgsstrategie“ nicht nur die Einhaltung des „Reinheitsgebots“ der Sinfonie, das ausgesprochen oder unausgesprochen hinter der deutschen Ablehnung der Sinfonischen Dichtung stand, sondern bewegte sich auch geschickt im konfliktreichen Spannungsfeld zwischen der in Deutschland tiefverwurzelten Auffassung von der Orgel als liturgisch-funktionalem Instrument und der Forderung nach Modernisierung und Anschluss an das Niveau des allgemeinen Konzertlebens. Denn nicht nur hinsichtlich programmatischer, sondern auch allgemein weltlich-sinfonischer Elemente war die Orgel ein „scheinbar unverfängliches“ Instrument. Indem Reger den Schwerpunkt seiner kompositorischen Tätigkeit im Bereich der Orgelmusik auf traditionelle sakrale Orgelgattungen legte, aber auch mit seiner insistierenden Berufung auf $\mathrm{Bach}^{69}$ und schließlich mittels verbaler, den Anteil weltlich-sinfonischer Elemente bagatellisierender Äußerungen verschleierte Reger das in Wahrheit durch und durch Sinfonische seiner Orgelmusik. Er kleidete, um in Meischeins Bild zu bleiben, weltlich-sinfonische Aspekte seines Orgelwerks in das Gewand sakraler Gattungen und konnte unter diesem Deckmantel formale und strukturelle Techniken und Charakteristika des Sonatensatzes anwenden, um sie - unangreifbar - mit einer Expressivität und Exzentrizität zu füllen, die selbst im Bereich weltlicher Sinfonik ihresgleichen suchten. Es ist in der Tat auffällig, dass in zeitgenössischen Rezensionen zu Regers Orgelwerken Aspekte des Sinfonischen vielfach ausgeblendet oder als Anknüpfung an Bach'sche Formmodelle und Idiome umgedeutet und überhöht werden. Gern wird dabei der „religiöse Charakter“ von Regers Kompositionen hervorgehoben. So heißt es in der Orgelzeitschrift Urania im Jahr 1902:

„Regers Werke sind sammt [sic!] und sonders als Emanationen einer religiös-sittlichen Künstlerpersönlichkeit [...] aufzufassen, so daß wir es nicht für Zufall, sondern für eine Fügung des Weltengenius halten, wenn Reger mit seinen Werken unmittelbar an Bach, den Orgelgewaltigen aller Zeiten, anknüpft und sein Stilprinzip zu dem seinigen macht, es aber wiederum durchdringend mit seinem eigenen, originalen Geiste. So ist es erklärlich, wenn uns beim Spielen und Hören Regerscher Werke Bachs Geist umweht [...]. Die vorwiegend religiöse Stimmung ist die Triebkraft in Regers romantischem Schaffen [...]. Und hierin im harmonischen Ausgleich des religiösen und sittlichen Moments seiner Kunst - erblicken

68 Meischein, „Dantes ,Inferno“ im symphonischen Gewand der Orgel“, S. 15.

69 Das Bedürfnis Regers nach Anerkennung und Unangreifbarkeit spielt eine zentrale Rolle in seiner Bach-Verehrung: „Hier kommen die geheimsten Wünsche und Sehnsüchte ins Spiel: Bach soll der ,Wundermann' sein, der Reger auf so magische Weise erleuchtet und gefördert hat. Je näher er dem ,Allvater' der Musik ist, desto überlegener ist er denen, die ihn angreifen. Der Wunsch nach einer möglichst umfassenden Identifikation mit Bach läßt die Bedeutung aller anderen, die auf Reger einwirkten, auf ein Mindestmaß schrumpfen. Bach wird hier zu einer Art Abwehrzauber, der die ,Dilettanten' in ihre Schranken weisen soll. [...] Er, der große, über allen Streit, über Tagesmoden, Parteien und Wertauffassungen erhabene ,Musikgottvater" wird als Schutzpatron beschworen." Johannes Lorenzen, Max Reger als Bearbeiter Bachs (= Schriftenreihe des Max-Reger-Instituts Bonn 2), Wiesbaden 1982, S. 50f.; siehe auch S. 48, Anm. 116. 
wir den Kardinalpunkt, welcher uns Reger zu einer der sympathischsten Künstlerpersönlichkeiten der Neuzeit macht und ihn uns im berechtigten Stolze, daß wir ihn haben, in die unmittelbare Nachbarschaft Bachs stellen läßt. "70

Natürlich erfuhr Regers Orgelwerk wegen seiner extremen Ausmaße in nahezu allen musikalischen Parametern auch viel Ablehnung, darunter die als unverständlich kritisierte Symphonische Phantasie. Dennoch überwiegt in der deutschen Rezeption, gerade angesichts der blühenden Orgelkultur im Nachbarland Frankreich, der Stolz auf einen neuen deutschen „Orgel-Heroen“, der einvernehmlich als der größte Orgelkomponist nach Bach gewürdigt wurde.

Ganz anders Frankreich, wo Regers Orgelwerk - wie auch sein übriges Schaffen - praktisch nicht wahrgenommen und, wo doch, vehement abgelehnt wurde. Die Ursachen für das auffällige Desinteresse der französischen Orgelfachwelt ${ }^{71}$ und des Orgelkonzertpublikums an Regers allein schon aufgrund seines immensen Umfangs unübersehbarem oder besser unüberhörbarem Orgelwerk ${ }^{72}$ sind vielfältig. Zunächst fiel Regers Lebens- und Schaffenszeit in die von dem Bedürfnis nach Abgrenzung und Unabhängigkeit von allem „Deutschen“ gekennzeichnete Epoche nach 1870, in der sich die französische Musik- und Orgelwelt auf ihre eigenen Traditionen und ihre gegenwärtigen musikproduktiven Kapazitäten besann. Die Erneuerung der französischen liturgischen Orgelmusik auf der Basis des Gregorianischen Chorals und viel mehr noch die französische Orgelsinfonik brachten eine Orgelkultur hervor, die sich allzu sehr von der auf dem protestantischen Choral und protestantischen Musiktraditionen basierenden Orgelmusik Regers unterschied, als dass ihr Wohlwollen oder auch nur Interesse hätte entgegengebracht werden können. Die Bereitschaft französischer Organisten, sich anderen kirchenmusikalischen Traditionen als der Gregorianik zuzuwenden, war mit der Aufnahme von einigen Choralvorspielen und -bearbeitungen Bachs in die katholische Liturgie bereits vollständig gesättigt, so dass es für Regers reichen Beitrag in diesem Bereich offensichtlich keinen Bedarf mehr gab. Schließlich waren die auf klangliche Dichte und Einheitlichkeit angelegten großen sinfonischen Orgeln Cavaillé-Colls ebenso wenig dazu geeignet, die Komplexität der Reger'schen Polyphonie adäquat wiederzugeben, wie der französische Liebhaber von Orgelmusik mit seiner Vorliebe für Miniaturen ${ }^{73}$ bereit war, sich auf in jeder Hinsicht maßlose Orgelmonumente, die zudem noch vornehmlich tragischen, wo nicht "gewaltsamen" Charakters waren, einzulassen.

70 Urania. Musik-Zeitschrift für Orgelbau, Orgel-und Harmoniumspiel 59 (1902), S. 20.

71 Tatsächlich wurde und wird nicht nur Regers Orgelschaffen, sondern sein gesamtes Werk in Frankreich kaum rezipiert. Bis heute „fehlt dieses immense und erstaunlich mannigfaltige Schaffen gänzlich auf französischen Konzertprogrammen, es ist inexistent in den Instrumentalklassen unserer Musikschulen oder unserer verschiedenen Konservatorien [...], ja es fehlt sogar in den Schallplattenregalen [...].“ Pierre Guillot, „Max Reger, Stiefkind der französischen Organisten?“, in: Reger-Studien 4. Colloque franco-allemand/Deutsch-französisches Kolloquium Paris 1987 (= Schriftenreihe des Max-Reger-Instituts Bonn IX), Wiesbaden 1989, S. 219-225; hier S. 219. Vgl. auch Françoise Andrieux, „Max Reger und Frankreich", in: Ebd., S. 151-168. Auch fast 30 Jahre nach Erscheinen dieser Artikel hat sich die Situation nicht grundsätzlich geändert.

72 Mit 211 auf 27 Opera verteilten Stücken übersteigt Regers Orgelwerk quantitativ sogar dasjenige von J. S. Bach.

73 Auch Widors und Viernes Orgelsinfonien wurden nicht als Ganzes dargeboten und gehört, sondern meist einzelne Sätze daraus. 
Desinteresse oder Ablehnung gegenüber der zeitgenössischen Orgelmusikproduktion des Nachbarlandes kennzeichnete umgekehrt jedoch auch die deutsche Orgelfachwelt. Zwar waren kleinere Orgelwerke französischer Komponisten Bestandteil des Konzertrepertoires vieler deutscher Organisten - nicht zuletzt in Ermangelung eigener zeitgenössischer Orgelmusik von hoher Qualität -, doch waren beispielsweise Widors acht Sinfonien op. 13 und op. 42 noch um 1890 in Deutschland weitgehend unbekannt. So bedauert der Herausgeber der Orgelzeitschrift Urania, Alexander Wilhelm Gottschalg, 1887, dass sich noch kein deutscher Organist dieser Werke angenommen habe: „[...] denn auf allen uns seither zugegangenen Orgelconzert-Programmen haben wir den Namen dieses Meisters leider noch nicht gefunden. " 74 Albert Schweitzer, der in beiden Orgelkulturen beheimatet war, drückt in seinem Aufsatz über die Deutsche und französische Orgelbaukunst und Orgelkunst von 1906 sein Bedauern über „die künstlerischen Grenzwälle“ aus, die „mehr als ein totales Nichtwissen um die Verhältnisse drüben“ widerspiegelten, nämlich „fast eine Unmöglichkeit, sich beim besten Willen zu verstehen."75 Eine Ursache dafür sieht er in der grundsätzlich verschiedenen Orgelbaukunst der beiden Länder: „Regers Werke sind auf der Orgel von Notre-Dame oder auf der von St. Sulpice unausführbar und Widors Symphonien sind auf deutschen Orgeln auch nur mit einer gewissen Vergewaltigung des Wesens und der Anlage des Instruments wiederzugeben. ${ }^{\text {"76 }}$

Orgelsinfonik mit oder ohne Orgelsinfonie: Beim Vergleich der beiden Orgelnationen Frankreich und Deutschland lässt sich zusammenfassend feststellen, dass der sinfonische Aspekt der Monumentalität und des Erhabenen die französische und deutsche konzertante Orgelmusik nach 1870 verbindet. In der französischen Orgelmusik war es die spezifische Klanglichkeit und herausragende technische Qualität und Neuartigkeit der Cavaillé-CollOrgeln, die im Zusammenwirken mit der französischen Musikästhetik und dem nationalen Neo-Katholizismus die französischen Orgelvirtuosen zur Komposition sinfonischer Orgelmusik inspirierte. Obwohl in Deutschland seit Liszts großen Orgelwerken der 1850er Jahre früher als in Frankreich sinfonische Aspekte, darunter vor allem Monumentalität und das zyklische Prinzip, Eingang in die Orgelmusik fanden - Aspekte, die den Beginn der französischen Orgelsinfonik mit César Franck unmittelbar beeinflussten - und später mit Max Regers freien Orgelwerken eine ausgeprägte motivische Arbeit hinzutrat, scheuten deutsche Orgelkomponisten offenbar aufgrund einer ungebrochenen sinfonischen Tradition und des daraus erwachsenen Beharrens auf dem „Reinheitsgebot" der Sinfonie sowie einer kirchlichprotestantisch geprägten Orgelanschauung vor der Gattungsbezeichnung Orgelsinfonie zurück. Französische Orgelkomponisten waren dagegen aufgrund einer musikhistorischen Entwicklung, in deren Zentrum im 19. Jahrhundert nicht das sinfonische Schaffen, sondern die Oper stand, freier von Skrupeln hinsichtlich der Übertragung der Sinfonie als Gattungsbegriff auf die Orgel. Beides, die französische Übertragung der Gattungsbezeichnung Sinfonie auf die Orgel ebenso wie ihre deutsche Ablehnung, liegt also nicht zuletzt in einer von nationalen und nationalistischen Tendenzen beeinflussten Musikästhetik begründet, die zu dem Paradox führte, dass der Begriff Orgelsinfonie als französische „Erfindung“ in die Gattungsgeschichte einging, während er in der deutschen konzertanten Orgelmusikproduktion, wo er aufgrund einer größeren Vielzahl an sinfonischen Aspekten angemessener erscheint als in der französischen, eben gerade nicht verwendet wurde.

74 Urania 44 (1887), S. 34.

75 Schweitzer, Deutsche und französische Orgelbaukunst, S. 1.

76 Ebd., S. 1f. 